\title{
Study on the Influence of Seat Adjustment on Occupant Head Injury Based on MADYMO
}

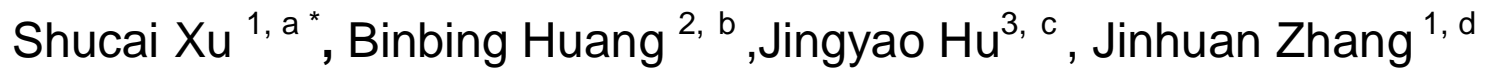 \\ ${ }^{1}$ State Key Laboratory of Automotive Safety and Energy, Department of Automotive Engineering, \\ Tsinghua University, Beijing 100084, China \\ ${ }^{2}$ Suzhou Automobile Research Institute, Tsinghua University, Suzhou 215000, China \\ ${ }^{3}$ BAIC Motor Corporation LTD., Beijing 101300, China \\ axushc@tsinghua.edu.cn, ${ }^{\mathrm{b}}$ huangbinbing@tsari.tsinghua.edu.cn, ${ }^{\mathrm{d}} \mathrm{zhjh} @ \mathrm{t}$ tsinghua.edu.cn
}

Keywords: Restraint System, Seat, HIC, Head Acceleration, MADYMO.

Abstract. Occupant head protection is very important in frontal impact. In this paper, a restraint system model was built with Hybrid $\square 50 \%$ dummy in MADYMO, and then the parameters of belt and airbag were adjusted to consummate the model. Then the effects of different seat longitudinal position and seatback angle on driver's head injury were analyzed. The level of occupant head injury was estimated with head acceleration peak value and HIC. The simulation results indicated that seat adjustment had obvious effects on occupant head protection. Over moving of seat longitudinal position and seat back angle could cause visible injury of occupant head, while an appropriate position enhanced the protection.

\section{Introduction}

With the development of global economy and the improvement in people's living standards, production and sales of vehicles are increasing rapidly as well as the speed of vehicle. As a result, vehicle accidents are also increasing in the last decade, and becoming more and more serious [1-3]. In collision safety, the scores of state crash regulations and China-New Car Assessment Program (C-NCAP) can reliably reflect the collision safety performance of a tested vehicle, providing the correct direction for vehicle occupant protection research [4, 5]. As the energy absorbing region is relatively small in a vehicle, occupant space and occupant restraint system should be better matched to ensure occupant's safety. Researchers in China have established the model for car restraint system, and conducted vehicle crash simulation calculation and sensitivity analysis of restraint system parameters, including airbag folding method, safety belt technology parameters and steering tube energy absorption design [6-11]. Vehicle seat is very important in restraint system, and plays a vital role in occupant protection, which is significantly different as the various seat position and seat back angle [12]. In this paper, a certain car was researched through taking some important evaluation parameters of European New Car Assessment Programme (Euro NCAP) as evaluation index, and establishing a relatively accurate restraint system model to analyze the impact of different seat position and seat back angle on driver's occupant head injury in side impact. The research expects to provide a basis for vehicle seat design and the adjustment of active protection parameters, and provides guidance for C-NCAP and seat adjustment of Collision Pre-judgment Technology.

\section{Restraint system modeling}

The CAD model of a certain vehicle was took as the LS-DYNA model, establishing the fundamental parameters of the structure size, location and constraint relationships, and then it was processed with software Hypermesh to generate LS-DYNA key file. The key file was imported into MADYMO software to establish the Facet model.

The model is shown in Fig. 1, including occupant space panel, floor, steering column and other components. The cushion and the backrest follow the Facet model, and the Contact Stiffness Curve was used to simulate the mechanical properties. Establish a three-point finite element model of seat belts, applying the pre-tightening and force-limited model. A finite element model of the airbag was 
established in the driver's side to simulate the expansion and the effects of the airbag. The Hybrid III 50th percentile dummy in MADYMO dummy library was used to conduct the measurement of the injury index.

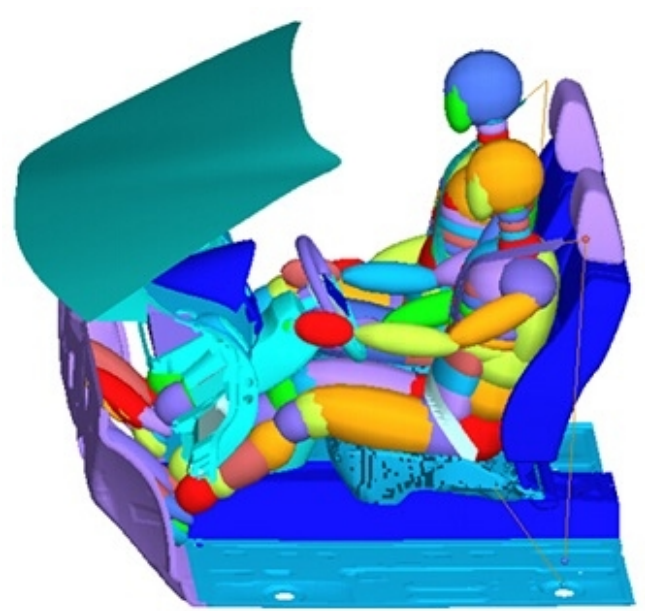

Fig. 1 MADYMO simulation model

Having completed vehicle simulation calculation with the LS-DYNA keyword file and obtained good benchmarking with real vehicle testing, we extracted the collision acceleration curve, the floor warping and panel backward curve, the steering column movement curve and other critical curves, which would be used as the input conditions of MADYMO operations. The time of collision simulation was set to $100 \mathrm{~ms}$, and the time step of $1 \mathrm{E}-6$.

\section{Airbag adjustment and simulation benchmarking}

The airbag's leaking rate is extremely important for the protection of the occupant's head, so the airbag parameters should be adjusted to the best during parameter design. As the most important airbag parameter is its air leaking rate CDEX. A series of adjustments were made to select the best CDEX according to the dummy's score of standard Euro NCAP evaluation, the peak value of the dummy's head acceleration and its HIC value. The comparison process of airbag adjustments is shown in Fig. 2, Fig. 3 and 4 shows HIC's impact on the peak value of head acceleration and CDEX's impact on HIC.

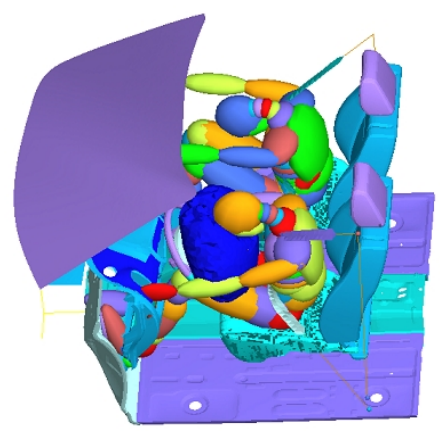

$\mathrm{CDEX}=1$

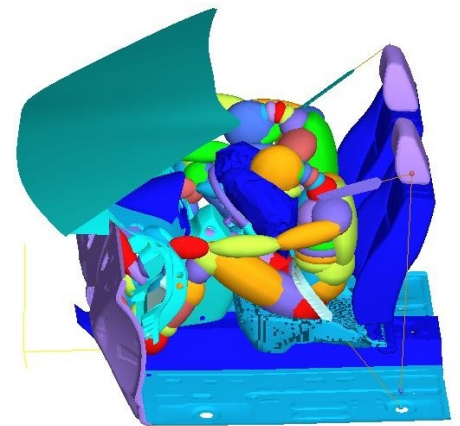

$\mathrm{CDEX}=5$

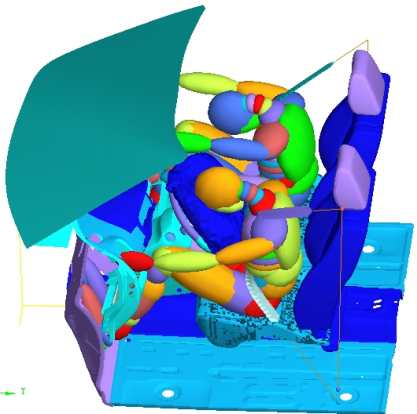

$\mathrm{CDEX}=8$

Fig. 2 Comparison of airbag adjustments 


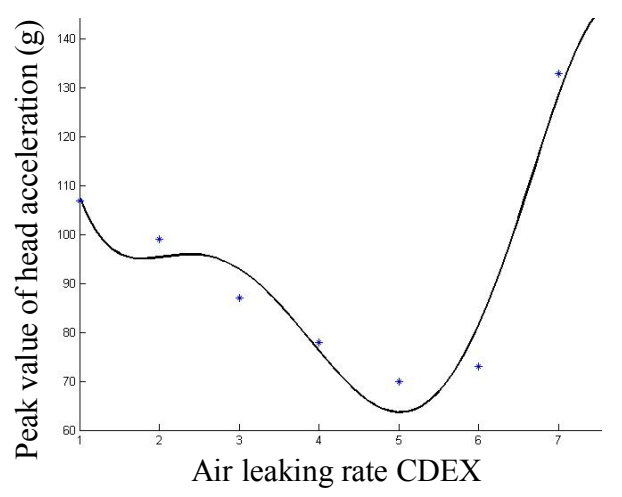

Fig. 3 HIC's impact on the peak value of head acceleration

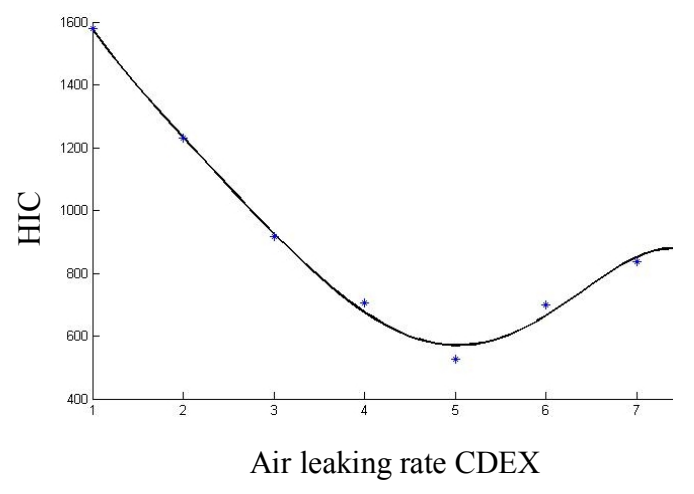

Fig. 4 CDEX's impact on HIC

As is shown in Fig. 2, Fig. 3 and Fig. 4 that, airbag stiffness is high and the contact area is small when airbag leaking rate is relatively low, so airbag cannot fully absorb energy and the injury of occupant's head will be serious. However, when airbag leaking rate is too high, air leaks out too quickly during a collision so that all the air has leaked out before the collision ended. In this case, the dummy's head will directly contact with the steering column, and airbag fails to perform the best protective effect.

The adequate contact area and time between occupant and airbag could be ensured in a collision when we set $\mathrm{CDEX}=5$. At this time, the protection effect of airbag was maximum. In consideration of establishing the best model and occupant head protection, we set the airbag leaking rate to 5 .

Simulation was conducted after establishing the model, which was adjusted according to real vehicle testing results. Fig. 5 shows the dummy's trajectory extraction after the adjustment.
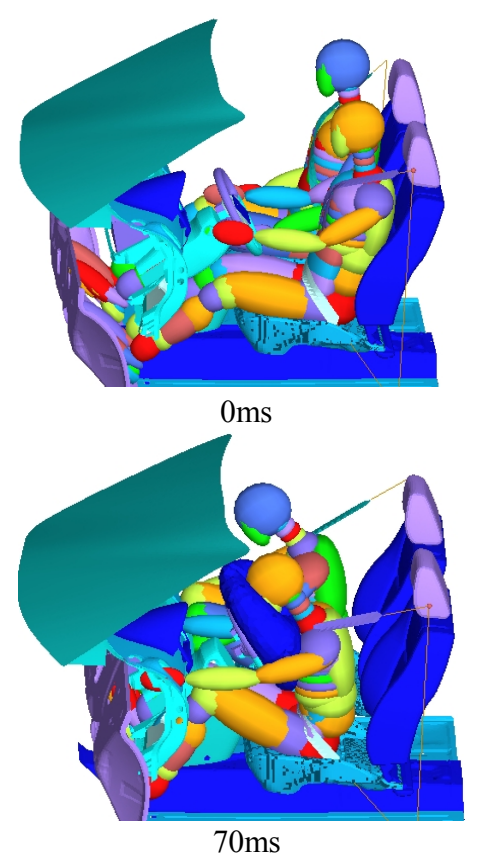
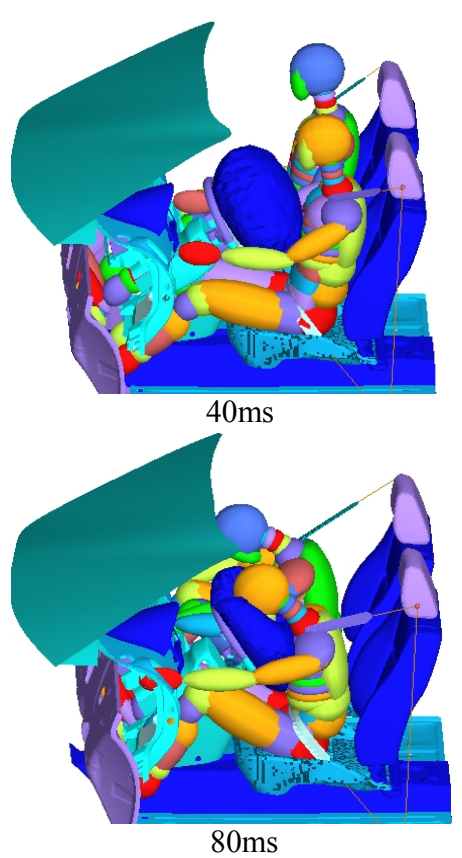
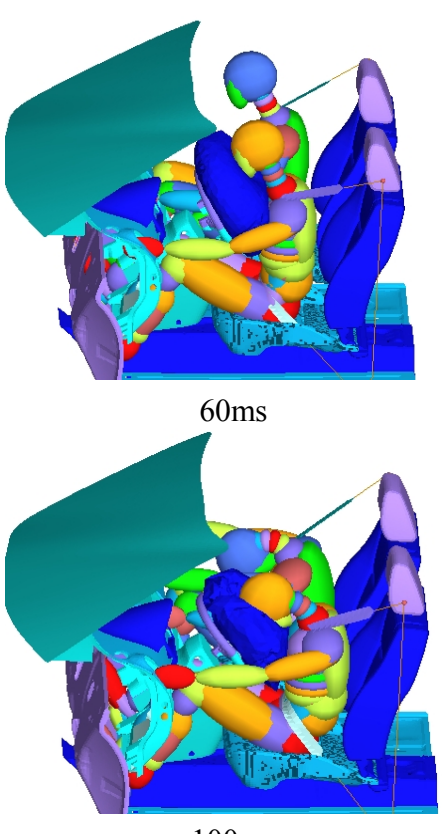

$100 \mathrm{~ms}$

Fig. 5 The dummy's trajectory by simulation

Fig. 6 and Fig. 7 shows the results of parameters benchmarking of real vehicle testing and simulation. As is shown, the parameters benchmarking of the B-pillar acceleration and seat belt force are good. The acceleration of B-pillar has a good reflection of the occupant restraint system's acceleration, and the seat belt force can well reflect the restraint system's protection on occupant. A good benchmarking of two parameters ensures the accuracy of evaluating occupant injury index through imposing acceleration loads. 


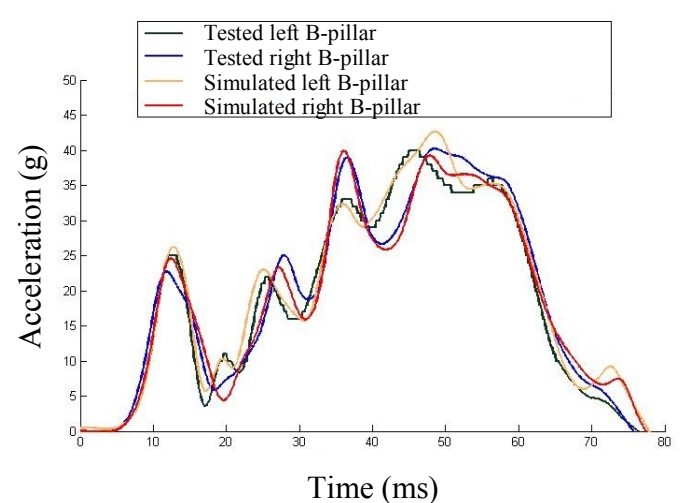

Fig. 6 Benchmarking of the B-pillar acceleration

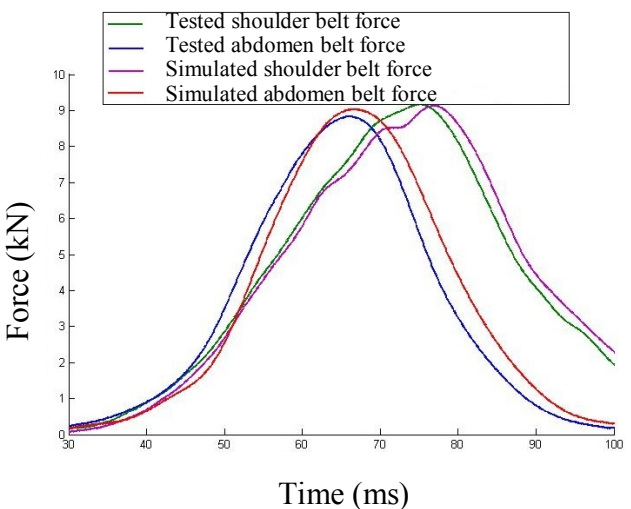

Fig. 7 Benchmarking of seat belt force

\section{Analysis of parameters' influence}

In a frontal vehicle collision, occupant injury mainly comes from two situations: directly contact with components of restraint system and self-collision inside occupant's body, while the latter will not be discussed in this paper. In the situation when occupant directly contact with restraint system, seat, belt and airbag play a vital role in occupant protection. As airbag parameters' adjustment has been discussed in the former part, this part will focus on seat parameters' adjustment, including analyzing the effects of different seat longitudinal position and seatback angle on driver's head injury. The level of occupant injury will be estimated with head acceleration peak value and HIC.

\section{The effects of different seat longitudinal position on occupant's head injury}

Fixed seat back angle at the factory default position, and curves of the driver's head injury were got from the seat longitudinal position adjustment. Fig. 8 and 9 shows the curve simulation process using quintic polynomial interpolation. As seen in Fig, head acceleration peak value and HIC value decrease firstly and then increase with the seat changes its longitudinal position. When the seat at original position (i.e. the displacement is zero), head acceleration peak value and HIC value at a lower level. The change of seat longitudinal position will cause a certain amount of increase in head acceleration peak value and HIC value, which is against the head protection. The contact of occupant and airbag will be ahead of time as the seat move forward, so that airbag has not been fully expanded in contact with the occupant. In this case, head injury will be more serious as the greater relative velocity. The more the seat move forward, the greater the influence will be.

Fig. 8 and Fig. 9 also indicated that the seat backward can have positive effects on occupant protection, but only to a certain extent; if the displacement is too large, there will be more severely negative effects. This can be explained as follows. As the occupant moves backward from the original position, safety belt can come into function, fully absorb occupant energy and protect head. But when the seat moves backward too much, all the air in the airbag will leak out before contacting the occupant, resulting in serious head injury of the occupant.

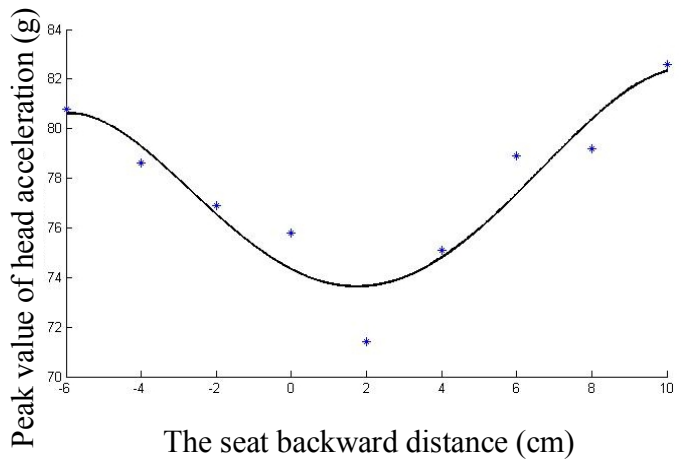

Fig. 8. Seat longitudinal position's impact on the peak value of head acceleration

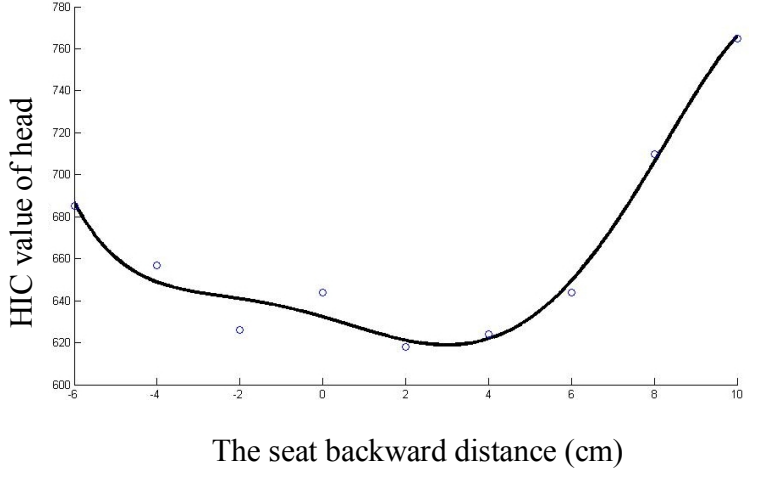

Fig. 9 Seat longitudinal position's impact on HIC value of head 
The suggested displacement of seat's backward movement is 0 to $4 \mathrm{~cm}$, to keep head acceleration peak value and HIC value at a relatively lower level.

\section{The influence of seatback angle on occupant's head injury}

Fixed the seat at the factory default position, and then adjusted its seatback angle and the dummy's sitting posture to make them fit better together. Next analyze the influence of seatback angle on dummy's head injury. As the seatback seldom rotate forward, this research only deals considered the cases that the seatback rotate backward.

As is shown in Fig. 10 and 11, the seatback angle does not have a big influence on occupant's head protection when it changes at a small range. However, when the seatback backward angle is too large, there will be a sharp decline in occupant's head protection, which is the same as the seat move backward too much. Both situations share the same mechanism. The influence of lower limbs and neck injury must be taken into account if the seatback angle continues to increase. When the seatback angle is between 0 to 3 degrees, the restraint system will have obvious protection on the occupant's head.

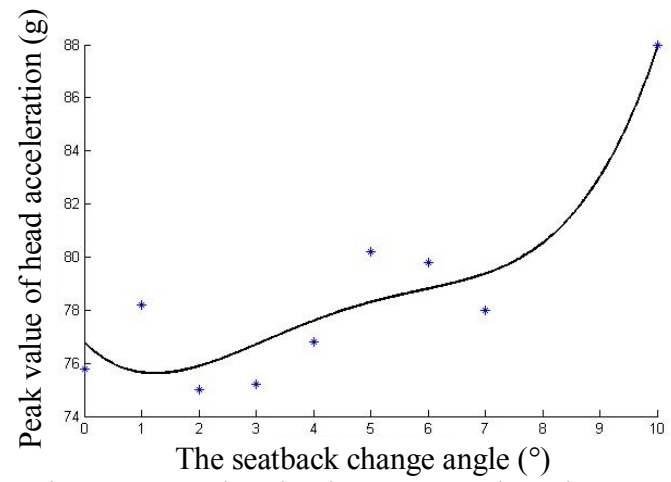

Fig. 10 Seatback change angle's impact on the peak value of head acceleration

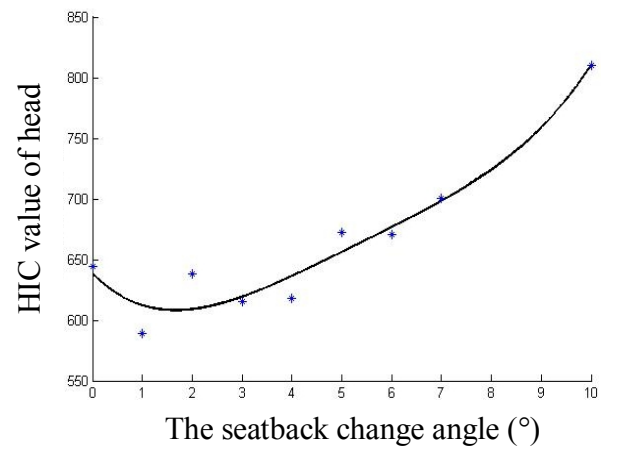

Fig. 11 Seatback change angle's impact on HIC value of head

\section{The combined effects of seat longitudinal position and seatback angle}

The seat longitudinal position and seatback angle have combined effects on head protection which both affect occupant's posture in a collision and the relative position in the restraint system. The following part will discuss the differences and relationships between the two factors with a full range of tests in nine degrees.

As is shown in Fig. 12 and Fig. 13, when the seat moves from -2 to $4 \mathrm{~cm}$, there will be maximum and minimum value in HIC curve, which has an obviously positive effect on occupant's head protection. And the difference between the two curves is obvious. When the seatback angle changes from 0 to 3 degrees, occupant's head injury will keep at a relatively low value in a wide range of seat longitudinal position. As is shown in Fig.14 and Fig.15, when the seat longitudinal position and seatback angle change, head acceleration peak value and HIC value share the same change trend.

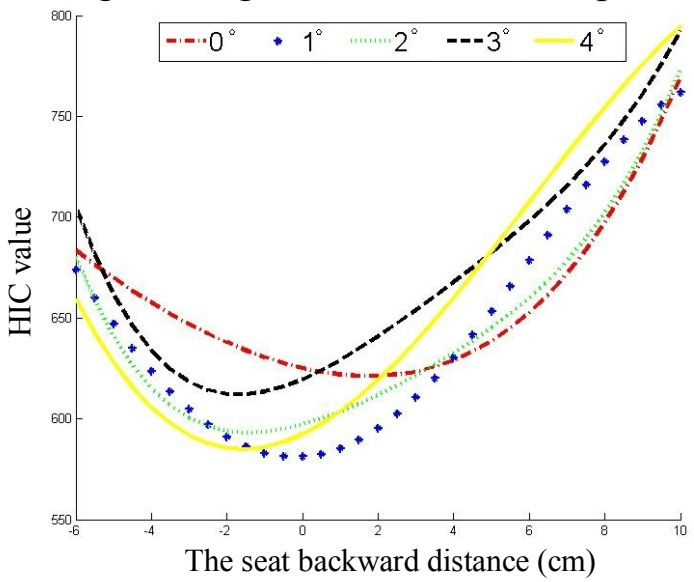

Fig. 12 HIC values change with seat translational when the seatback angle changes from $0^{\circ}$ to $4^{\circ}$

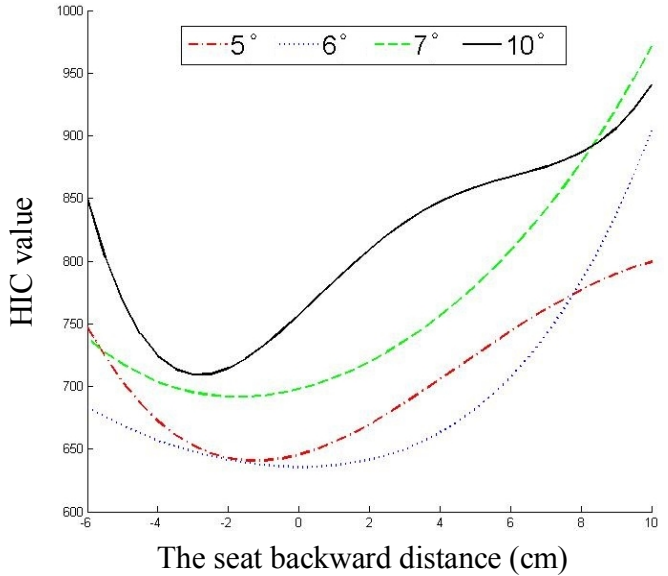

Fig. $13 \mathrm{HIC}$ values change with seat translational when the seatback angle changes from $5^{\circ}$ to $10^{\circ}$ 


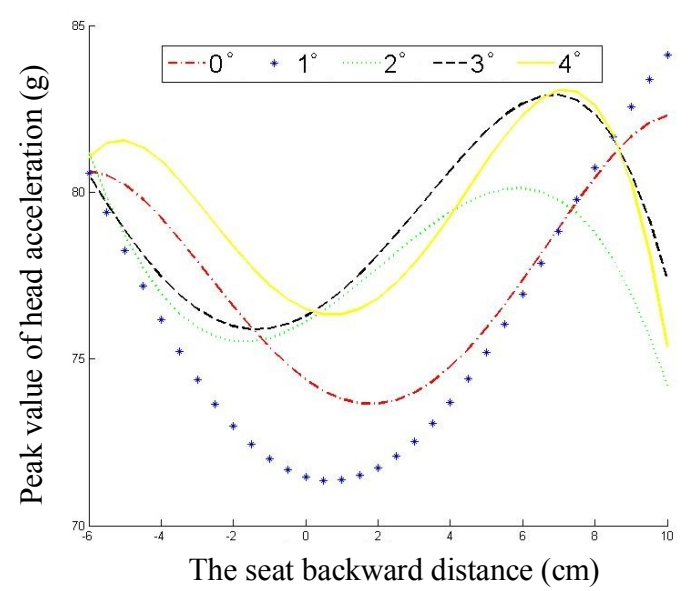

Fig. 14 Peak value of head acceleration change with seat translational when the seatback angle changes from $0^{\circ}$ to $4^{\circ}$

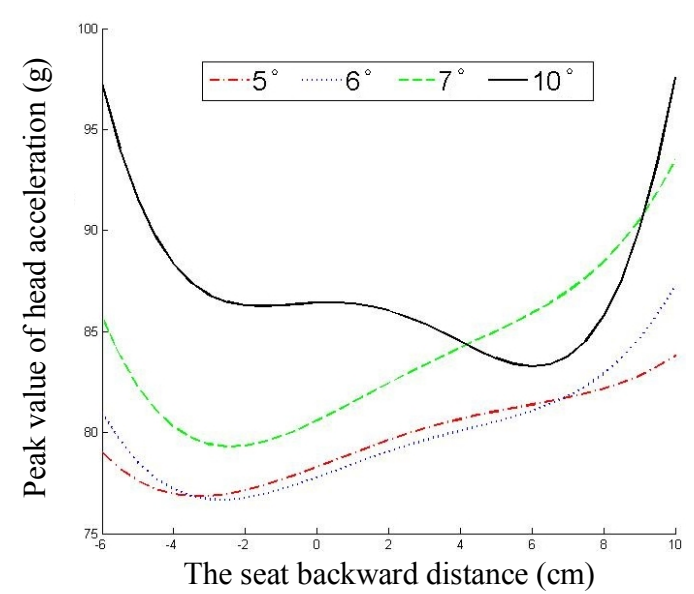

Fig. 15 Peak value of head acceleration change with seat translational when the seatback angle changes from $5^{\circ}$ to $10^{\circ}$

As the comprehensive analysis above, both the seat longitudinal position and seatback angle value have a beneficial range for the occupant's head protection. And the protection effect will be even more significant when the two value ranges are superimposed.

Fig. 16 and 17 displays the 3-dimension surface generated by MATLAB. The surfaces clearly show the best range of the seat longitudinal position and seatback angle. Occupant's head will be well protected, when the seat longitudinal displacement is between 0 and $4 \mathrm{~cm}$, seatback angle 0 and 3 degrees. Meanwhile, the protective area is relatively large, which greatly reduced the accuracy requirements for adjusting seat parameter to the ideal area.

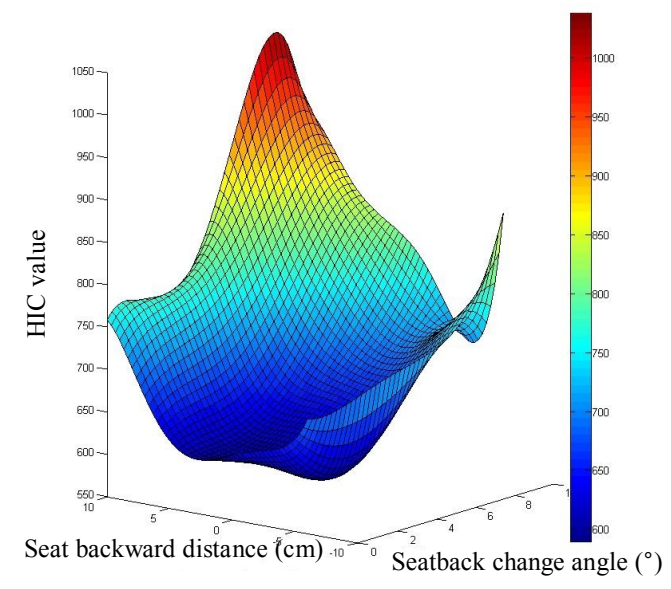

Fig. 16 3-dimension surface of HIC values

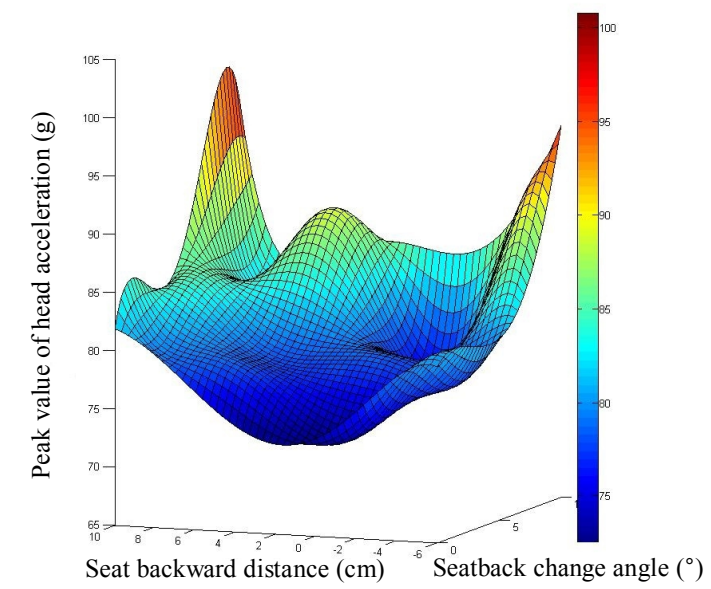

Fig. 17 3-dimension surface of peak value of head acceleration

\section{Conclusions}

This research analyzed the influences of seat parameters on occupant's head injury with computer simulation and determined the best adjustment range. The main conclusions are as follows:

(1) When designing the parameters of vehicle restraint system, the matching of airbag parameters occupies an important position, which will greatly depends on the parameter design of the seats and belts, and also has an obvious influence on their protection effect.

(2) When airbag and safety belts parameters are fixed, the adjustments of the seat longitudinal position and seatback angle will have a significant influence on occupant's head protection. And the two parameters have an optimized superimposed area. 
(3) The adjustments of the seat longitudinal position and seatback angle have mutual influence with each other on occupant's head protection. And the interaction cannot be clarified as a simple linear superimposed relationship.

(4) There is a relatively flexible range for the adjustments of the seat longitudinal position and seatback angle, which allows a relatively larger fault tolerance for the improvements of collision pre-judging technology. And the possibility of realizing active seat function increases greatly in this technology.

\section{Acknowledgements}

This work was supported by the National Natural Science Foundation of China (Grant no. 51305223), Science and Technology Project of Suzhou (Grant no. SYG201426).

\section{References}

[1] J. Yang, Review of injury biomechanics in car-pedestrian collisions, International journal of vehicle safety. 1(1) (2005) 100-117.

[2] F. Li, J.K. Yang, A study of head-brain injuries in car-to-pedestrian crashes with reconstructions using in-depth accident data in China, International Journal of Crashworthiness. 15(2) (2000) 117-124.

[3] R. Schoeneburg, T. Breitling, Enhancement of active and passive safety by future PRE-SAFE systems, 2005 ESV Conference, Washington DC Paper. (2005) 05-0080.

[4] J.H. Zhang, H.L. Du, C.S. Ma, Automotive design crash safety, Beijing, 2010.

[5] S.L. Huang, J.H. Zhang, X.D. Wang, Automotive crash and safety, Beijing, 2000.

[6] Z.C. Song, J.H. Zhang, F.Z. Kong, Simulation of minibus occupant restraint system, Journal of Tsinghua University. 44(11) (2004) 1536-1539.

[7] H.H. Wang, Y. Huang, H. Liu, Simulation test and evaluation method of occupant ejection from side windows in the traffic accident, Journal of Automotive Safety and Energy. 5(4) (2014) 349-353.

[8] J.Y. Liu, Q. Liu, D.Z. Wang, Euro-NCAP pedestrian upper leg new test protocol effect to the front end styling and packaging design, Journal of Automotive Safety and Energy. 5(4) (2014) 354-359.

[9] L. Yang, Y.L. Gu, Structural optimization for reducing knee slider displacement in offset deformable barrier crash, Journal of Automotive Safety and Energy. 5(4) (2014) 367-370.

[10]J.H. Zhang, Z.G. Li, S.C. Xu, Dynamic response and energy relationship of a passenger's different parts in vehicle crash, Journal of Automotive Safety and Energy. 1(1) (2010) 23-29.

[11]D.Z. Wang, C.X. Yu, Frontal crashworthiness structure design of mini electric passenger cars, Journal of Automotive Safety and Energy. 1(1) (2010) 49-52.

[12]R.H. Ge, L. Zang, H.H. Wang, Analysis on the influence for the protection on frontal impact by vehicle seat cushion obliquity, Journal of Mechanical Engineering. 45(11) (2009) 230-234. 